\title{
Income Distribution and Price Controls: Targeting a Social Safety Net During Economic Transition
}

By: Michael Alexeev and James Leitzel

Working Paper Number 281

March 1999 
Draft: Comments welcome

Income Distribution and Price Controls: Targeting a Social Safety Net During Economic Transition

\author{
Michael Alexeev \\ Department of Economics \\ Indiana University \\ Bloomington, IN 47405 \\ (812) 855-7103 \\ malexeev@indiana.edu \\ and \\ J ames Leitzel \\ Social Science Collegiate Division \\ University of Chicago \\ (773) 702-8555 \\ j-leitzel@uchicago.edu
}

Revised, March 1999

\begin{abstract}
During the ongoing post-communist economic transitions, the relative well-being of many people is changing rapidly, and governments are not well positioned to accurately measure individual living standards. Under such circumstances, continued price controls over basic consumer goods within the state sector, and the associated queuing, can form a serviceable device for targeting poor people for subsidies. With a fixedprice state sector and free-price parallel markets, rich people might choose to avoid queues and shop in the free markets, while poor people would prefer to pay low nominal prices and queue in the state sector. The targeting of subsidies through queues, therefore, can be accomplished even if the government has no information on individual income or living standards. When the alternative to price controls is a poorly targeted explicit social safety net, the resource cost of queues might be more than compensated for by an improvement in the targeting of subsidies.
\end{abstract}

Keywords: price controls, tax evasion, queue-rationing, economic 
transition, income distribution.

We are grateful for financial support from the National Council for Soviet and East European Research. Earlier versions of this paper were presented at the New Economic School, the University of Essex, and Indiana University. We are grateful to seminar participants, and to anonymous referees, for helpful comments. Errors are the responsibility of the authors.

Income Distribution and Price Controls: Targeting a Social Safety Net During Economic Transition

Michael Alexeev and J ames Leitzel

\section{Introduction}

The provision of an adequate social safety net is a leading concern during economic transitions from socialism to capitalism. The safety net in socialist societies consists of explicit provisions such as pensions and disability payments, as well as other features inherent in the system of central planning. In particular, the policies of full employment and low fixed prices for most basic consumer goods within the state sector are major elements of the social safety net in socialist economies. During the transition, however, privatization (or the implementation of hard budget constraints) and price liberalization undermine these implicit social welfare protections. ${ }^{1}$ Transitional economies, therefore, have enacted additional explicit provisions, such as unemployment benefits and minimum wages, to protect the welfare of some of their citizens.

A fundamental difficulty in providing benefits to needy individuals is to distinguish those who are in need from others who can afford to 
provide subsidies. Many programs in the West are means-tested, only available to those whose incomes fall below some threshold. Such targeting of benefits is by no means perfect, even in the absence of fraud, because official income is an imperfect indicator of welfare. The targeting of social safety provisions is even more problematic in transitional societies, however. First, the informal economy tends to be very large, so official income captures a smaller percentage of total monetary income. ${ }^{2}$ Second, the in-kind provision of goods and services often is substantial and variable, diminishing the correlation between monetary income and welfare. Third, government authorities have little experience with the implementation and enforcement of the new explicit social welfare policies. It has been claimed that many of those who receive unemployment benefits, for example, actually hold jobs. ${ }^{3}$

The difficulty of identifying poor people in transitional societies is matched by its importance. While there are many problems with the data and their interpretations, the socialist states tended to have distributions of income that were egalitarian relative to most Western market economies. ${ }^{4}$ During the transitional years, these countries generally have seen a sharp increase in measured income inequality. The increasing (and increasingly visible) gap between the haves and have-nots frequently is cited as leading to an anti-reform backlash, and in promoting the electoral prospects of former communists or other opponents of transition. 
One policy often advocated by those who are concerned about the distributional impacts of reform is either to delay price liberalization, or, after a liberalization, to return to price controls on basic consumer commodities within the state sector. Western economists typically lament such policies because of the resource misallocations, including queuing, that accompany price controls, and because such controls would seem to slow down the transformation to a market economy.

Price controls, nevertheless, have continued to play a large role in some transitional economies, and especially in Russia. While most central price controls were eliminated in Russia in 1992, prices of basic consumer goods frequently are controlled by local authorities. The EBRD estimated that one-third of Russian prices remained under control in $1995 .^{5}$ The controls can take the direct form of mandated price ceilings, or the indirect form of limitations on profit rates. The controls also can be applied informally, through governmental threats to retaliate in some manner (perhaps through anti-monopoly provisions) against firms that charge high prices. Many Russian localities have coupled their price controls with internal trade restrictions, to prevent the "export" of pricecontrolled goods to other Russian regions. ${ }^{6}$

Why are price controls so popular in countries that are engaged in a transition to a market economy? The purpose of this paper is to argue that queue rationing can be a serviceable device for targeting poor people 
for subsidies, particularly during the reform period, and this feature adds to the attractiveness of price controls during transition. With a fixed-price state sector and free-price parallel markets, rich people might choose to avoid queues and shop in the free markets, while poor people would prefer to pay low nominal prices and queue in the state sector. The targeting of subsidies through queues, therefore, can be accomplished even if the government has no information on individual income or living standards. When the alternative to price controls is a poorly targeted explicit social safety net, the resource cost of queues might be more than compensated for by an improvement in the targeting of subsidies.

A substantial literature has developed on the relative merits of queuing for distributing goods among heterogeneous consumers. Sah (1987) shows that poor people prefer queue-rationing to free markets, in a model with fixed output, no parallel markets, and where everyone, rich and poor alike, queues for goods under the price-control regime. Alexeev (1991) and Polterovich (1993) derive similar results in models that also include general equilibrium effects and free-price, parallel markets. ${ }^{7}$ Boycko (1992) and Osband (1992), while not primarily concerned with distributional issues, add production into their models of queue-rationing. Price controls then carry a further cost in terms of lost output, as waiting in queues reduces the time available for work. Our model focuses on the distributional consequences of price controls, but also incorporates a 
production cost to queuing. This cost is muted, however, by the fact that only the least productive workers stand in line for goods, while more productive workers purchase goods in the parallel markets.

Berkowitz (1996) is an earlier paper that addresses the question of the persistence of queue rationing during reform. His model considers a capacity-constrained market with both state and private firms, where the local government values consumer surplus more highly than producer surplus. He shows that in situations where capacity constraints in private firms lead to high prices, the local government should set a low price in the state sector and induce queue-rationing. In a sense, such a policy is an efficient indirect regulatory tool, inducing the private firms to lower their prices. Our model complements Berkowitz (1996) by considering situations where the government values a relatively equal distribution of economic welfare, again finding that state-sector price controls can form an optimal second-best policy.

The generalization of the argument in this paper is simply that initial conditions are very important for transitional socialist economies. Explicit social safety nets that do not include price controls are perhaps the preferable means for protecting social welfare in Western market economies--though even in these settings, the targeting of subsidies can be improved by using indirect means, such as workfare. ${ }^{9}$ When starting from a situation of state socialism, however, continuing price controls 
can play a significant role during the transition. Likewise, continued state ownership of some enterprises might also form part of a safety net during the transition, even if the desired final destination involves nearcomplete privatization..$^{10}$ There are many substitute means available to provide a social safety net. The preferred alternative in transitional socialist societies may well be quite different from that appropriate for advanced market economies.

The remainder of this paper is organized as follows. Section 2 presents an illustrative model of three different allocation mechanisms: free markets, queue rationing and parallel markets, and imperfectly targeted subsidies to poor people. Section 3 compares social welfare under these regimes through graphical and numerical analysis, while section 4 extends the analysis to a combined targeting-price control scheme. Section 5 contains a brief discussion and conclusions.

\section{An Illustrative Model}

There are two types of individuals, rich (denoted by the subscript $r$ ) and poor (denoted by the subscript p). Let the total size of the population be normalized to 1 , with the proportion of poor people denoted by $v$, and the proportion of rich people by 1-v. Rich and poor people differ in their wage rates, assumed to be fixed and exogenous, at $w_{r}$ and $w_{p}$, respectively. 
Both rich and poor have a total of $L$ hours per period available; leisure hours are denoted by $l_{r}$ and $l_{p}$, and hours of work are given by $h_{r}$ and $h_{p}$. We will normalize with $L=1$ : hours of work, plus hours of leisure, plus hours of queuing, sum to 1 for every individual. There is one consumption good, with the quantities consumed given by $x_{r}$ and $x_{p}$. Consumers have a Cobb-Douglas utility in leisure and consumption, with each component entering with exponent 0.5 , given by $U_{r}=l_{r}^{1 / 2} \cdot x_{r}^{1 / 2}$ and $\mathbf{U}_{\mathrm{p}}=l_{\mathrm{p}}^{1 / 2} \cdot \mathbf{X}_{\mathrm{p}}^{1 / 2}$.

Assume that workers are paid their marginal product, and that the production function of the consumption good for both rich and poor people is linear in hours of labor, with slope equal to marginal product: poor individuals, who have marginal product $w_{p}$, produce in total $Q_{p}=v \cdot w_{p} \cdot h_{p}$, and the rich, with marginal product $w_{r}$, produce $Q_{r}=(1-v) \cdot w_{r} \cdot h_{r}$. Total output $Q$, therefore, is $Q=v \cdot w_{p} \cdot h_{p}+(1-v) \cdot w_{r} \cdot h_{r}$. Time spent queuing, then, not only directly decreases utility, but also holds the potential to reduce total output, by detracting from the hours of labor supplied by workers who wait in line.

The "social planner" is assumed to value both individual welfare and a relatively egalitarian distribution of living standards. (Alternatively, it could be assumed that the individuals themselves care about distribution.) Social welfare, W, will be taken to be encapsulated by a constant-elasticity-of-substitution function: $W=\left[v U_{p}^{\varepsilon}+(1-v) U_{r}^{\varepsilon}\right]^{1 / \varepsilon}$, with 
$\varepsilon \leq 1 .{ }^{11}$ When $\varepsilon=1$, welfare is the sum of individual utilities, and there is no social gain to redistribution of utility (though redistribution of income can still influence social welfare.) Lower levels of $\varepsilon$ are associated with higher social concern for distribution; as $\varepsilon$ approaches $-\infty$, the social welfare function depends only on the utility of the most worse-off individual $\left(\mathrm{W}=\min \left[\mathrm{U}_{\mathrm{p}}, \mathrm{U}_{\mathrm{r}}\right]\right)$. Further, a perfectly equal distribution of individual utility $\left(U_{p}=U_{r}\right)$ yields social utility equal to the sum of individual utilities; for any $\varepsilon<1$, increasing departures from equality, everything else equal, result in diminishing social welfare.

\section{Case 1: No Intervention}

As a benchmark, it is useful to consider the outcome under a free market, with no price controls or social safety net. The general problem facing consumers, then, is:

$$
\begin{aligned}
& \max U_{i}=l_{i}^{1 / 2} \cdot x_{i}^{1 / 2} \\
& \boldsymbol{l}_{\mathrm{i}}, \mathbf{x}_{\mathrm{i}} \\
& \text { subject to: } l_{i}+h_{i}=1, l_{i} \geq 0, x_{i} \geq 0 \text {, and } \\
& P \cdot x_{i}=w_{i} \cdot h_{i} \text {, for } i=p, r \text {. }
\end{aligned}
$$

The first constraint reflects the fact that with no queuing under free markets, people spend all of their time either working or at leisure. Solving the "no intervention" problem yields $l_{i}^{*}=1 / 2, h_{i}^{*}=1 / 2$ and $x_{i}^{*}=w_{i} / 2 P$, for $i=p, r$. 
At equilibrium, the total quantity demanded equals the total quantity supplied: $\mathrm{vx}_{\mathrm{p}}{ }^{*}+(\mathbf{1}-\mathrm{v}) \mathrm{x}_{\mathrm{r}}^{*}=\mathrm{Q}=\mathrm{v} \cdot \mathrm{w}_{\mathrm{p}} \cdot \mathrm{h}_{\mathrm{p}}{ }^{*}+(\mathbf{1}-\mathrm{v}) \cdot \mathrm{w}_{\mathrm{r}} \cdot \mathrm{h}_{\mathrm{r}}{ }^{*}$, and substituting for $h_{i}^{*}$ and $x_{i}^{*}$ yields a free-market equilibrium price of $P^{*}=1$. A poor person achieves utility $U_{p}=W_{p}^{1 / 2} / 2$, and a rich person has utility $U_{r}=W_{r}^{1 / 2} / 2$.

\section{Case 2: Price Controls}

When the social safety net consists of a price-controlled sector, there exist two channels through which the consumption good can be secured. In the state sector, the good is sold at a controlled price P', while in the free-market sector, the price is $P$. We are interested in the case of a completely separating equilibrium, where all the poor consumers shop in the state sector and all of the rich consumers shop in the free markets. While we assume (see the introduction, and the formalization of a targeted safety net) that the government cannot identify poor and rich people ex ante, in the equilibrium with price controls that is examined, ex post the poor people will be those who are shopping in the state sector. ${ }^{12}$

A rich person, then, solves the same problem as in the free-market case, with solutions $l_{r}^{*}=1 / 2, h_{r} *=1 / 2$, and $x_{r}^{*}=w_{r} / 2 P$. A poor person shops only in the state sector, and devotes $t$ hours in queuing per unit of the good purchased. ${ }^{13}$ A poor person therefore solves the problem:

$$
\begin{aligned}
& \max _{l_{p}, h_{p}, X_{p}} U_{p}=l_{p}^{1 / 2} \cdot x_{p}^{1 / 2} \\
& \text { subject to: } l_{p}+h_{p}+t x_{p}=1, \quad l_{p} \geq 0, h_{p} \geq 0, x_{p} \geq 0 \text {, and }
\end{aligned}
$$




$$
\mathbf{P}^{\prime} \cdot \mathbf{x}_{\mathrm{p}}=\mathbf{w}_{\mathrm{p}} \cdot \mathbf{h}_{\mathrm{p}} \cdot
$$

Solving this problem yields $l_{p}{ }^{*}=1 / 2, h_{p}{ }^{*}=P^{\prime} / 2\left(t w_{p}+P^{\prime}\right)$, and $x_{p}{ }^{*}=w_{p} / 2\left(t w_{p}+P^{\prime}\right)$.

At equilibrium, as in the free-market case, the total quantity demanded equals the total quantity supplied: $\mathbf{v x}_{\mathrm{p}}{ }^{*}+(\mathbf{1 - v}) \mathrm{x}_{\mathrm{r}}{ }^{*}=\mathbf{Q}=$ $v \cdot w_{p} \cdot h_{p} *+(1-v) \cdot w_{r} \cdot h_{r} *$ For a given per-unit wait time $t$, this condition establishes the equilibrium price P* in the free-market sector. The wait time must be such to support our assumption of a fully separating equilibrium; i.e., wait times cannot be so high that poor individuals would find it in their interest to shop in the free markets, nor so low as to induce rich people to shop in the state sector. Since the effective price in the state sector is $t w_{p}+P^{\prime}$ for poor people and $t w_{r}+P^{\prime}$ for rich people, and the equilibrium price in the free-market sector is $\mathbf{P}^{*}$, these conditions imply that:

$$
\mathbf{t w}_{\mathrm{p}}+\mathbf{P}^{\prime} \leq \mathbf{P}^{*} \text {, or } \mathbf{t} \leq\left(\mathbf{P}^{*}-\mathbf{P}^{\prime}\right) / \mathbf{w}_{\mathrm{p}} \text {, and } \mathbf{t w}_{\mathrm{r}}+\mathbf{P}^{\prime} \geq \mathbf{P}^{*} \text {, or } \mathbf{t} \geq\left(\mathbf{P}^{*}-\mathbf{P}^{\prime}\right) / \mathbf{w}_{\mathbf{r}} \mathbf{}
$$

The shortest queue time, then, that is still consistent with a fullyseparating equilibrium, is $t=\left(P^{*}-P^{\prime}\right) / w_{r}$. Employing this queue time in the market-clearing condition $\mathrm{vx}_{\mathrm{p}}{ }^{*}+(1-v) \mathrm{x}_{\mathrm{r}}{ }^{*}=\mathrm{v} \cdot \mathrm{w}_{\mathrm{p}} \cdot \mathrm{h}_{\mathrm{p}}{ }^{*}+(1-v) \cdot \mathrm{w}_{\mathrm{r}} \cdot \mathrm{h}_{\mathrm{r}} *$, allows for the determination of the equilibrium price, P*. The complexity of the expression for $\mathrm{P}^{*}$ necessitates the use of numerical examples, in section 3, to conduct social welfare comparisons between the price control regime and the targeted safety net regime. ${ }^{14}$ Because the authorities can always make the price control high enough to be non-binding, resulting in no 
queuing, an optimal price control regime cannot be dominated (in terms of social welfare) by the no intervention case.

One issue that arises in this setup is the source of the price subsidy. How will the state be able to sell the consumption good below its cost of production? Consider the following scenario. The good is produced exclusively by private firms and the state can tax the free market sales at the rate of $\left(P^{*}-1\right)$ per unit, while subsidizing the sales at controlled prices by (1-P') per unit. ${ }^{15}$ Under this arrangement, as in the no intervention case, the producers continue to receive $P=1$ for each unit of the good. It is straightforward to show that in equilibrium the state budget will balance:

$$
v\left(1-P^{\prime}\right) x_{p}^{*}=(1-v)\left(P^{*}-1\right) x_{r}^{*} \text {, or that } v x_{p}^{*}+(1-v) x_{r}^{*}=v P^{\prime} x_{p}^{*}+
$$

$(1-v) \mathbf{P}^{*} \mathbf{x}_{\mathrm{r}}^{*}$

Indeed, because the individual budget constraints yield $\mathrm{P}^{\prime} \mathrm{x}_{\mathrm{p}}{ }^{*}=\mathrm{w}_{\mathrm{p}} \mathrm{h}_{\mathrm{p}}{ }^{*}$ and $\mathbf{P}^{*} \mathbf{X}_{r}^{*}=w_{r} h_{r}^{*}$, the state budget balance expression above is equivalent to the market-clearing equilibrium condition.

\section{Case 3: Imperfectly Targeted Redistribution}

One alternative to state-sector price controls as a social-safety net is a targeted redistribution plan. The targeting, however, is not perfect, in the sense that not all of the subsidies go to poor people. We assume that a poor person cannot appear to be rich; however, a rich person may incorrectly be viewed as poor (and hence a potential recipient of a 
targeted subsidy). To be specific, the government has available a signal of reliability $\gamma, 0 \leq \gamma \leq 1$, such that the signal indicates that a rich person is indeed rich with probability $\gamma_{.}{ }^{16}$ A person who is indicated to be rich is then taxed a lump-sum amount (per period) equal to T. Total tax collections are (1-v) $\gamma \mathrm{T}$, reflecting the fact that some people who are actually rich are judged to be poor. The money collected in this fashion is then redistributed to people who are indicated poor. The transfer to a person judged to be poor, therefore, is $\mathbf{S}$ (for Subsidy) $=(1-v) \gamma T /[v+(1-\gamma)(1-$ v)].

The taxes and subsidies will influence an individual's labor supply and consumption. With homothetic preferences, however, the balancedbudget lump-sum transfers will not affect the equilibrium price, which remains at the non-intervention level of $P^{*}=1$. There are now two "types" of rich individuals: type $r 1$ (occurring with probability $\gamma$ ) that is correctly viewed as rich and hence taxed, and type $r 2$ (occurring with probability 1$\gamma$ ) that is signaled as being poor, and hence receives a subsidy. The first type will solve the problem:

$$
\begin{aligned}
& \max U_{r 1}=l_{r 1}^{1 / 2} \cdot x_{r 1}^{1 / 2} \\
& \boldsymbol{l}_{\mathrm{r} 1}, \mathbf{x}_{\mathrm{r} 1} \\
& \text { subject to: } l_{\mathrm{r} 1}+h_{\mathrm{r} 1}=1, l_{\mathrm{r} 1} \geq 0, h_{\mathrm{r} 1} \geq 0, \mathrm{x}_{\mathrm{r} 1} \geq 0 \text {, and } \\
& \text { P. } \mathbf{x}_{\mathrm{r} 1}=\mathbf{w}_{\mathrm{r}} \cdot \mathbf{h}_{\mathrm{r} 1}-\mathbf{T} \text {. }
\end{aligned}
$$


Employing $\mathrm{P}^{*}=1$, this problem has interior solution $l_{\mathrm{r} 1}{ }^{*}=\left(\mathrm{w}_{\mathrm{r}}-\mathrm{T}\right) / 2 \mathrm{w}_{\mathrm{r}}$, $h_{r 1}^{*}=\left(w_{r}+T\right) / 2 w_{r}$, and $\mathbf{x}_{\mathrm{r} 1} *=\left(\mathbf{w}_{\mathrm{r}}-\mathrm{T}\right) / 2$.

The problem for type $\mathbf{r} 2$ is identical, except that the budget constraint is now $P \cdot x_{r 2}=w_{r} \cdot h_{r 2}+S$, yielding solutions $l_{r 2} *=\left(w_{r}+S\right) / 2 w_{r}$, $h_{r 2} *=\left(w_{r}-S\right) / 2 w_{r}$, and $x_{r 2} *=\left(w_{r}+S\right) / 2$. Poor people solve the same problem as type $r 2$, except that they have the lower wage rate, $w_{p}$. So, $l_{p}^{*}=\left(w_{p}+S\right) / 2 w_{p}$, $h_{p}^{*}=\left(w_{p}-S\right) / 2 w_{p}$, and $x_{p}^{*}=\left(w_{p}+S\right) / 2$. With a lump-sum tax and subsidy scheme and the Cobb-Douglas preferences employed here, those who are taxed increase their labor supply (and hence their contribution to output), while those who are subsidized work less. ${ }^{17}$

The utility achieved by type 1 rich individuals is $U_{r 1}=\left(l_{r 1} *\right)^{1 / 2} \cdot\left(x_{r 1} *\right)^{1 / 2}=$ $\left(w_{r}-T\right) / 2 w_{r}^{1 / 2}$, and the utility of type 2 rich individuals is $U_{r 2}=\left(w_{r}+S\right) / 2 w_{r}^{1 / 2}$, or, substituting for $\mathbf{S}$, $U_{r 2}=\left(w_{r}+[(1-v) \gamma T /[v+(1-\gamma)(1-v)] 1) / 2 w_{r}^{1 / 2}\right.$. The utility achieved by a poor person is $U_{p}=\left(w_{p}+S\right) / 2 w_{p}^{1 / 2}$. In the case of a targeted safety net, social welfare is: $\mathbf{W}=\left[\mathbf{v} \mathbf{U}_{\mathbf{p}}^{\varepsilon}+(\mathbf{1}-\mathbf{v})_{\gamma} \mathbf{U}_{\mathrm{r} 1}^{\varepsilon}+(\mathbf{1}-\mathbf{v})(\mathbf{1}-\gamma) \mathbf{U}_{\mathrm{r} 2}^{\varepsilon}\right]^{1 / \varepsilon}$.

As the size of the tax $T$ increases, two limitations must be taken into account. The first is that, for $\mathbf{T}$ sufficiently large, the constraint that poor people work a non-negative number of hours becomes binding. Second, at some point $\mathbf{T}$ is so large that the taxed rich are made worse off than the subsidized poor. In practice, however, the incentive to work 
productively would be undermined by such a severe redistribution scheme. At such tax rates, those rich who cannot hide their income (i.e., who are identifiable as rich) would be expected to pool with the poor in terms of their productivity: the disincentive to work productively at high tax rates implies that the marginal product $w_{r}$ would not be sustained by productive but highly taxed workers. Further, once the taxed rich are no better off than the subsidized poor, increases in $\mathrm{T}$ will increase inequality.

\section{Simulations and Analysis}

In this section, we explore some of the properties of the model through a series of numerical and graphical examples. For all of the examples that are examined, $w_{p}$ is normalized to one.

The first example and the associated graphs involve the following parameter values:

$\varepsilon=-1$, implying that the government has some concern about distribution;

$v=8$, so the majority of individuals are poor;

$w_{r}=11$, indicating that rich individuals are much more productive than poor individuals;

and, $\gamma=33$, so the signal only correctly identifies one-third of the rich individuals. 
For Graph 1a, the controlled price in the state sector under the queuing regime is set arbitrarily at $P^{\prime}=5$. (This is not the optimal controlled price for the given parameters, though similar results are obtained when the targeting regime is compared with the optimal price control. See the discussion below.) Under these circumstances, the market-clearing price in the free price sector can be determined to be (approximately) $\mathrm{P}^{*}=\mathbf{1 . 4 5}$ and the equilibrium queue time is $\mathrm{t}^{*}=086$. Graph 1a indicates the relative desirability of price controls versus imperfect targeting, as the size of the tax $\mathbf{T}$ under the targeting regime changes. The vertical axis plots the ratio of social welfare under queuing to social welfare under targeting, minus one, so that positive values indicate higher welfare under queuing, and negative values indicate higher welfare under targeting. In this case, the larger the tax, the more desirable targeting is relative to queue-rationing, at least until the size of the tax becomes large relative to the earnings of the rich people. (Recall that as $\mathbf{T}$ gets large, the constraint that poor people work a non-negative number of hours becomes binding.) The break-even amount of the targeted tax is approximately 5.32: for $5.32<\mathrm{T}<10$, the targeting regime is preferred to the queuing regime with controlled price $\mathrm{P}^{\prime}=5$. High tax rates, however, are problematic: in this example, for $\mathrm{T}>5.96$, the welfare of the subsidized poor exceeds the welfare of the taxed rich. The potential for high- 
productivity workers to mimic the productivity of poor workers suggests that a tax above 5.96 would not be feasible.

As noted above, similar welfare comparisons arise when the optimal targeting regime (i.e., the size of the lump-sum $\operatorname{tax} T$ is chosen optimally, in terms of social welfare) is compared with the optimal price-control regime (i.e., where the level of the price control is chosen optimally.) Under some circumstances, the optimal targeting regime will dominate, from the point of view of social welfare, the optimal price control regime, and under other circumstances, vice versa. The tendency (as in Graph 1a) is for the optimal targeting regime to set the tax as high as possible, subject to the constraint that the utility of the taxed rich is no less than that of the subsidized poor. In not all circumstances, however, do higher lump-sum taxes produce higher welfare under a targeting regime. If the proportion of poor people is sufficiently small, the inequality engendered by the imperfect targeting--some of the ex ante identical rich are mistakenly subsidized, while the others are taxed--can provide one rationale for limiting the size of the tax in a targeting regime.

Graph $1 \mathrm{lb}$ employs the same basic parameters $\left(v=8, w_{r}=11, \gamma=33\right.$, and $\varepsilon=-1$ ) as in Graph 1a. In this example, however, the size of the tax under the targeting regime is fixed at its optimal feasible value of $T=6.22$. Graph $1 \mathrm{~b}$ again provides welfare comparisons under the two safety net alternatives, though for varying values of the controlled price, $\mathrm{P}^{1} \cdot{ }^{18}$ Note 
that it is not the case that the relative desirability of the queuing regime decreases monotonically as the controlled price increases. With the parameter values used in graph $\mathbf{1 b}$, the queuing regime is socially preferred for .1x $<\mathrm{P}^{\prime}<3 y$. While all else equal, poor people would prefer to pay a lower controlled price for their goods, one important factor that is not constant as $\mathrm{P}^{\prime}$ changes is output. Low controlled prices lead to long lines, and long lines lead to decreased labor supply and diminished output. If the output effect is sufficiently strong, social welfare need not increase as the controlled price falls. Graph 1c indicates the relationship between total output and the controlled price with the given parameters.

The relative desirability of the optimal queuing and targeting regimes strongly depends on the four basic parameters of the model, $v, w_{r}$, $\gamma$, and $\varepsilon$. The role of $\gamma$, the reliability of the government's signal about incomes, is the most straightforward. For any given tax rate (including the optimal rate) and with $\varepsilon<1$, the benefits of targeting are monotonically increasing in $\gamma$. At the same time, the value of $\gamma$ does not affect social welfare under queuing. So, the advantage of an imperfectly targeted social welfare regime relative to a queuing regime is also monotonically increasing in $\gamma$.

The influence of the other parameters on the relative desirability of optimal targeting and queuing regimes is less clear cut, and analytical 
methods have not yielded comparative statics results. Nevertheless, both simulations and intuition are suggestive.

Consider first the influence of the degree of social concern for real income distribution. Other things being equal, the dead-weight losses and output declines associated with queuing imply that if the redistributional motive is weak ( $\varepsilon$ is close to 1 ), either the free market or a targeting regime are preferable to price controls. As the distributional motive becomes stronger ( $\varepsilon$ declines), the importance of the redistributive aspects of queuing rise relative to the dead-weight losses that accompany price controls. Meanwhile, the problems for social welfare under a targeting regime caused by imperfect information about real incomes become more severe. The relative desirability of queuing as compared to targeting can, therefore, be expected to vary inversely with $\varepsilon$.

Let us now turn to the relationship between the proportion of poor in the society, v, and the relative social welfare under queuing and targeting. In the separating equilibria that are examined in the queuing regime, only the poor choose to queue. Given queue length, then, the deadweight loss due to queuing declines in v. While equilibrium queue length is affected by the value of $v$, our simulations suggest that this effect is secondary. If this tendency is true in general, then queuing performs it redistributive function better as the proportion of the poor falls. Simultaneously, the smaller is $v$, the larger the perverse 
distributional effect associated with imperfect targeting, that of mistakenly subsidizing rich people: for a given $\gamma<1$, more rich are subsidized as $\mathbf{v}$ declines. Therefore, we expect the relative usefulness of queuing vis-à-vis targeting to fall as the proportion of the poor rises. Graph $2 a$ employs the same values for the wage of the rich $\left(w_{r}=11\right)$ and for the reliability of the income signal $(\gamma=33)$. It depicts those combinations of $\mathbf{v}$ and $\varepsilon$ for which social welfare under the optimal queuing regime equals social welfare under an optimal (feasible) targeting regime. Consistent with our intuitive analysis, a larger emphasis on redistribution and a smaller proportion of poor people tend to favor a queuing regime as a social safety net.

Finally, consider the difference in the productivity of the rich and the poor as expressed by the value of $w_{r}$ (Recall that $w_{p}$ is normalized to one.) A smaller value of $w_{r}$ implies that the output losses associated with queuing are more important, because the contribution of poor people to output is relatively large. This effect reduces the attractiveness of queuing as a redistribution device. Also, small $w_{r}$ means that the free market allocation is relatively egalitarian, reducing the role of distributional concerns.

Graphs $\mathbf{2 b}$ and $2 c$ provide some flavor for how the comparison among regimes is influenced by changes in the relative productivity of the rich. In both graphs, the reliability of the government's income signal, $\gamma$, 
remains at $\mathbf{0 . 3 3}$, as in the other reported simulations. For Graph $2 \mathrm{a}$, once again the "redistribution" parameter $\varepsilon$ is set equal to 0.2 , while the graph depicts those combinations of $v$ and $w_{r}$ for which social welfare under the optimal targeting regime equals social welfare under the optimal queuing regime. Note that higher $w_{r}$ favors the queuing regime, and as in Graph $2 a$, a lower proportion of the poor also favors queuing. Graph $2 \mathrm{c}$ involves $v$ fixed at $\mathbf{0 . 8}$, and illustrates those combinations of $\varepsilon$ and $\mathbf{w}_{\mathrm{r}}$ for which social welfare under the optimal targeting regime equals social welfare under the optimal queuing regime. Once again, a higher $w_{r}$ and a higher $\varepsilon$ (a decreased emphasis on redistribution) make targeting relatively more attractive.

One generalization that can be offered from these simulations is that the relative desirability of price controls compared with a targeted safety net is closely connected to the government's interest in redistribution, and how well the government can actually tax income. The dead-weight losses and output falls associated with queuing imply that if there is no redistributional motive $(\varepsilon=1)$, either the free market or a targeting regime are preferable to price controls. For any level of $\varepsilon$, effective targeting depends not only on the quality of the signal $(\gamma)$, but also on the magnitude of the tax. It may be that high levels of $\mathrm{T}$ either result in adverse work incentives, or they are impossible to enforce: $\gamma$ could be a decreasing function of $T$, and tax revenues may be maximized 
at a relatively low level of $\mathbf{T}$. Under these circumstances, either $\mathbf{T}$ or $\gamma$ will perforce be low, and targeting will not be an attractive option.

\section{Combining Targeting and Price Controls}

Rather than being mutually exclusive, explicit taxation and price controls are used in combination in many transitional countries. Does such a combination offer an improvement over either or both of the redistributional regimes employed in isolation?

To address this question within the framework of the model, consider the following combined scheme. First, the government implements some (imperfectly) targeted redistribution; then, with their post-transfer incomes, consumers can purchase the good either on the free market or, after queuing, at a state-controlled price. The targeting results in three different types of consumers: the (now subsidized) poor, the taxed rich, and the (incorrectly) subsidized rich. In a separating equilibrium, the rich (both types of whom have the same opportunity cost of time) must not find it in their interest to wait in line with the poor: once again, we choose the minimum waiting time consistent with separation.

Simulations reveal that, while generally the imposition of (optimal) price controls following imperfect targeting is social welfare-improving, this is not always the case. Because of the dead-weight losses associated 
with queuing, there are at least three situations in which there is no value to supplementing an imperfect targeting scheme with price controls. First, as in the case of price controls in isolation, if the government has little interest in utility redistribution ( $\varepsilon$ approximately equal to 1 ), then the addition of price controls following targeting offers no social welfare improvement. Second, if the targeting regime itself is nearly perfect $(\gamma$ approximately one), then the optimal distribution can nearly be achieved with targeting, and there is no gain to supplementing the direct tax and transfer scheme with a price control that induces a dead-weight loss. Third, if the productivity difference between workers is very small to begin with $\left(w_{p}\right.$ is very close to $\left.w_{r}\right)$, then again, there is little social loss from the uneven distribution of utility, and price controls will not be helpful. But in general, as noted, a welfare program that combines imperfectly targeted redistribution with state-sector price controls will be more desirable than either system in isolation, if social welfare is dependent upon distribution.

\section{Conclusions}

We have demonstrated the possibility that price controls and statesector queue rationing can be preferable to imperfectly-targeted income subsidies in providing a social-safety net. The advantage of price controls in targeting subsidies is perhaps greatest in the transitional socialist 
countries, for two reasons. First, these nations have familiarity with the administration of price controls in state-owned stores. Second, the measures available for means testing social spending are likely to be very imprecise, and those most in need of subsidies could change quickly throughout the reform period. In a sense, our model presented an optimistic assessment of the ability to target subsidies, in that all truly poor people were identified as poor by the government. In real-world safety nets, some needy individuals "fall through the cracks," not receiving benefits for which they qualify. Taking this possibility into consideration would add to the relative desirability of price controls.

Nevertheless, there are costs to price controls other than those included in our model, and these must be considered in formulating policy. Price controls may be evaded in a variety of ways, from bribes to government officials to theft of the goods (and diversion to free markets) by production, retail or transportation employees. ${ }^{19}$ It is unlikely that the rents created by the price controls would then flow to relatively poor people, i.e., the targeting of the price-control safety net could be undermined. A similar problem could result within the framework of the model, if the controlled price does not generate a separating equilibrium, and some rich people acquire price-controlled goods. Another possibility is that the opportunity cost of time (which determines the willingness to wait in line for goods) and overall economic welfare are not highly and 
positively correlated. (In our model, those with the lowest incomes are also those with the lowest marginal opportunity cost of time.) Again, this would reduce the relative targeting advantage of state-sector price controls. With multiple goods, however, the targeting of price controls can be enhanced by instituting controls only on those goods (generally, basic consumer commodities) that are intensely consumed by the poor.

A further danger with transitional price controls is that they could become permanent, remaining in place even after sufficiently reliable information over economic welfare is available to efficiently implement Western-style targeted subsidies. Perhaps the largest danger is that the state-sector price controls could lead to further restraints on private economic activity. For example, the government might have difficulty collecting the tax on sales of the good to rich individuals, and hence be unable to finance the subsidy on sales to the poor. Under these circumstances, the state might choose to compel producers to supply some output at low rates, extend price controls to the non-state sector, or prohibit "exports" of the good to non-price controlled regions. Producers might then lose money, and the state might respond by expanding compulsory output quotas, or move to direct state ownership of production facilities. At the extreme, such a snowballing of controls could unintentionally re-establish a planned economy..$^{20}$ Despite these potential problems, however, price controls have some desirable features. When the 
alternatives are themselves far from first best, limited price controls and queue-rationing within the state sector can offer one element of a serviceable social-safety net. 


\section{References}

Alexeev, M. (1991). "If Market Clearing Prices are So Good, Then Why Doesn't (Almost) Anyone Want Them? Journal of Comparative Economics 15:380-390.

Alexeev, M., and Kaganovich, M. (1995). "Distributional Constraints on the Speed of Privatization." Economics Letters 48: 213-219.

Atkinson, A. B. and Micklewright, J . (1992) Economic Transformation in Eastern Europe and the Distribution of Income, Cambridge: Cambridge University Press.

Barzel, Y. (1974). "A Theory of Rationing By Waiting." Journal of Law and Economics 17(1): 73-95.

Bates, R. (1981). Markets and States in Tropical Africa: The Political Basis of Agricultural Policies, Berkeley: University of California Press.

Berkowitz, D. (1996). "On the Persistence of Rationing Following Liberalization: A Theory for Economies in Transition." European Economic Review 40: 1259-1280.

Berkowitz, D., and DeJ ong, D. N. (1997). "Observations on the Speed of Transition in Russia: Prices and Free Entry." Workshop proceedings, National Research Council, Task Force on Economics of Transition, National Academy Press, forthcoming.

Besley, T., and Coate, S. (1991). "Public Provision of Private Goods and the Redistribution of Income." American Economic Review 81: 979-984.

Besley, T., and Coate, S. (1992). "Workfare versus Welfare: Incentive Arguments for Work Requirements in Poverty-Alleviation Programs." American Economic Review 82: 249-261.

Boycko, M. (1992). "When Higher Incomes Reduce Welfare: Queues, Labor Supply, and Macro Equilibrium in Socialist Economies." Quarterly Journal of Economics 107: 907-920.

European Bank for Reconstruction and Development (1995). Transition Report 1995. London: EBRD. 
Leitzel, J . (1998). "Goods Diversion and Repressed Inflation: Notes on the Political Economy of Price Liberalization." Public Choice 94: 255-266.

---- (1997). "Lessons of the Russian Economic Transition," Problems of Post-Communism, J anuary-February, pp. 49-57.

(1995). Russian Economic Reform. London: Routledge.

Morduch, J ., Brooks, K., and Urinson, Y. M. (1994). "Distributional Consequences of the Russian Price Liberalization." Economic Development and Cultural Change 42: 469-484.

Murrell, P., Dunn, K. T., and Korsun, G. (1996). "The Culture of PolicyMaking in the Transition from Socialism: Price Policy in Mongolia." Economic Development and Cultural Change 45: 175-194.

Osband, K. (1992). "Economic Crisis in a Shortage Economy." Journal of Political Economy 100: 673-690.

Polterovich, V. (1993). "Rationing, Queues, and Black Markets." Econometrica 61 (1): 1-28.

Prell, M. A. (1996). "Which Allocation System is More Effective in Getting a Commodity to Those Who need it Most? " Journal of Comparative Economics 22: 165-178.

Russian Economic Trends, Vol. 4, No. 4 (1995). Government of the Russian Federation, London: Whurr Publishers.

Sah, R. K. (1987). "Queues, Rations, and Market: Comparisons of Outcomes for the Poor and Rich." American Economic Review 77(1): 6977.

Sachs, J . (1993) Poland's Jump to the Market Economy. Cambridge: MIT Press.

Shleifer, A., and Vishny, R. (1992). "Pervasive Shortages Under Socialism." Rand Journal of Economics 23: 237-246.

Shleifer, A., and Vishny, R. (1993). "Corruption." Quarterly Journal of Economics 108: 599-617. 
Stahl, D.O., and Alexeev, M. (1985). "The Influence of Black Markets on a Queue-Rationed Centrally Planned Economy." Journal of Economic Theory 35: 234-250.

Weitzman, M. L. (1991). "Price Distortion and Shortage Deformation, or What Happened to the Soap? " American Economic Review 81: 401-414.

Weitzman, M. L. (1977). "Is the Price System or Rationing More Effective in Getting a Commodity to Those Who Need it Most? " Bell Journal of Economics 8: 517-524.

Graph 1a: The ratio of social welfare under queuing to social welfare under targeting, minus 1 , as a function of the tax $\mathrm{T}$. $\left(w_{p}=1, w_{r}=11, \gamma=0.33, \quad v=0.8, \varepsilon=-1, \quad P^{\prime}=0.5\right)$

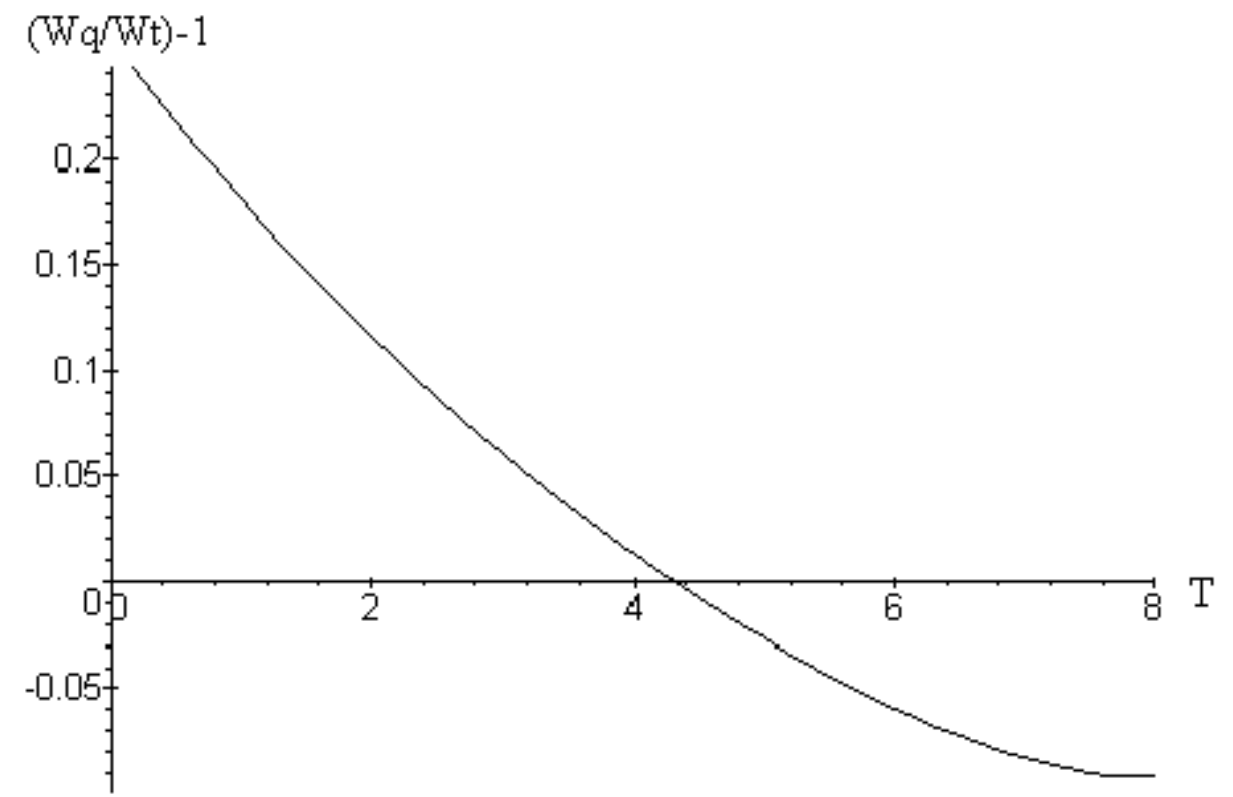


Graph 1b: The ratio of social welfare under queuing to social welfare under targeting, minus 1 , as a function of the controlled price $\mathrm{P}^{\prime} .\left(\mathrm{w}_{\mathrm{p}}=1, \mathrm{w}_{\mathrm{r}}=11, \gamma=0.33, \mathrm{v}=0.8, \varepsilon=-1, \mathrm{~T}=6.22\right)$

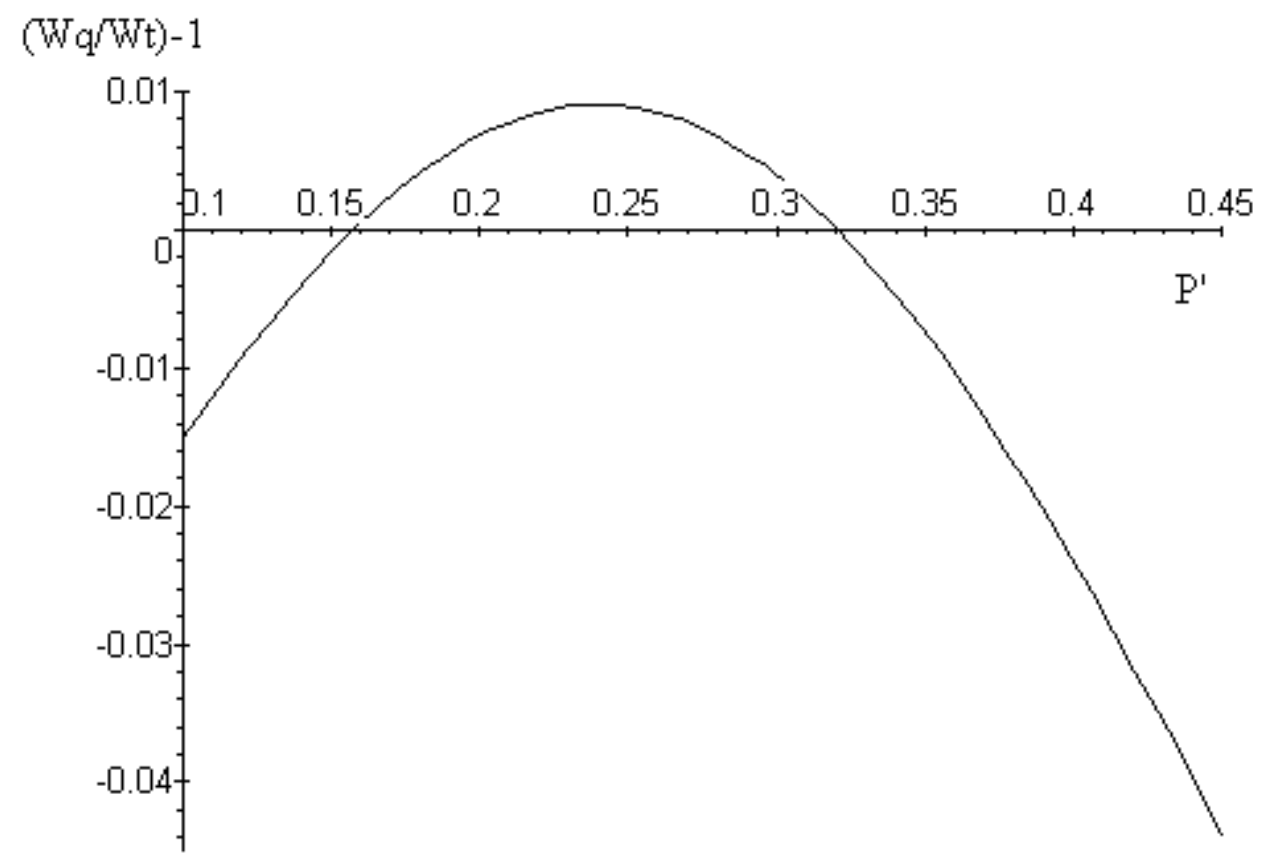


Graph 1c: Total output (Q) as a function of the controlled price $\left(P^{\prime}\right)$.

$\left(\mathrm{w}_{\mathrm{p}}=1, \mathrm{w}_{\mathrm{r}}=11, \quad \gamma=0.33, \mathrm{v}=0.8, \mathrm{~T}=6.22, \varepsilon=-1.\right)$

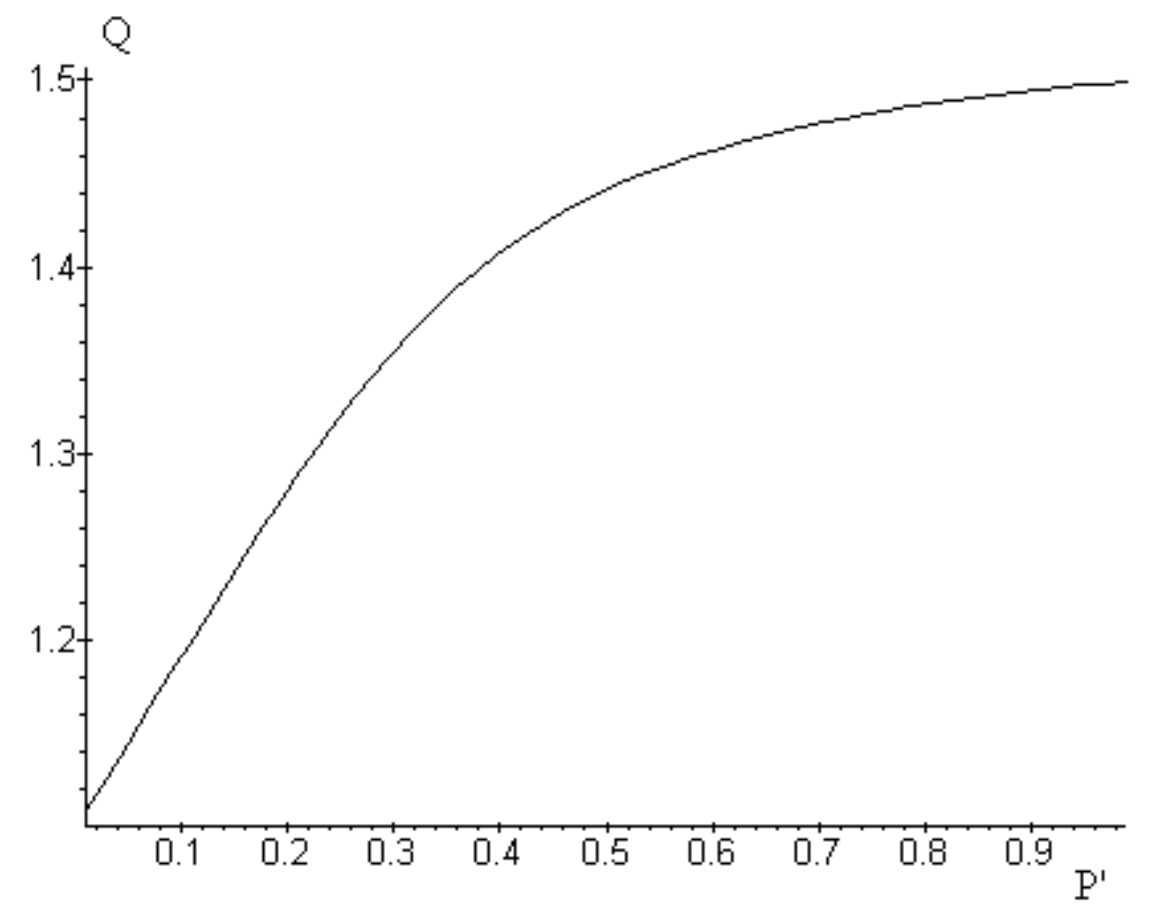


Graph 2a: Combinations of $\varepsilon$ and $v$ such that social welfare under queuing (Wq) equals social welfare under targeting (Wt), and the regions where $\mathrm{Wq}>\mathrm{Wt}$ and $\mathrm{Wt}>\mathrm{Wq}$.

$\left(w_{p}=1, w_{r}=11, \gamma=0.33\right)$

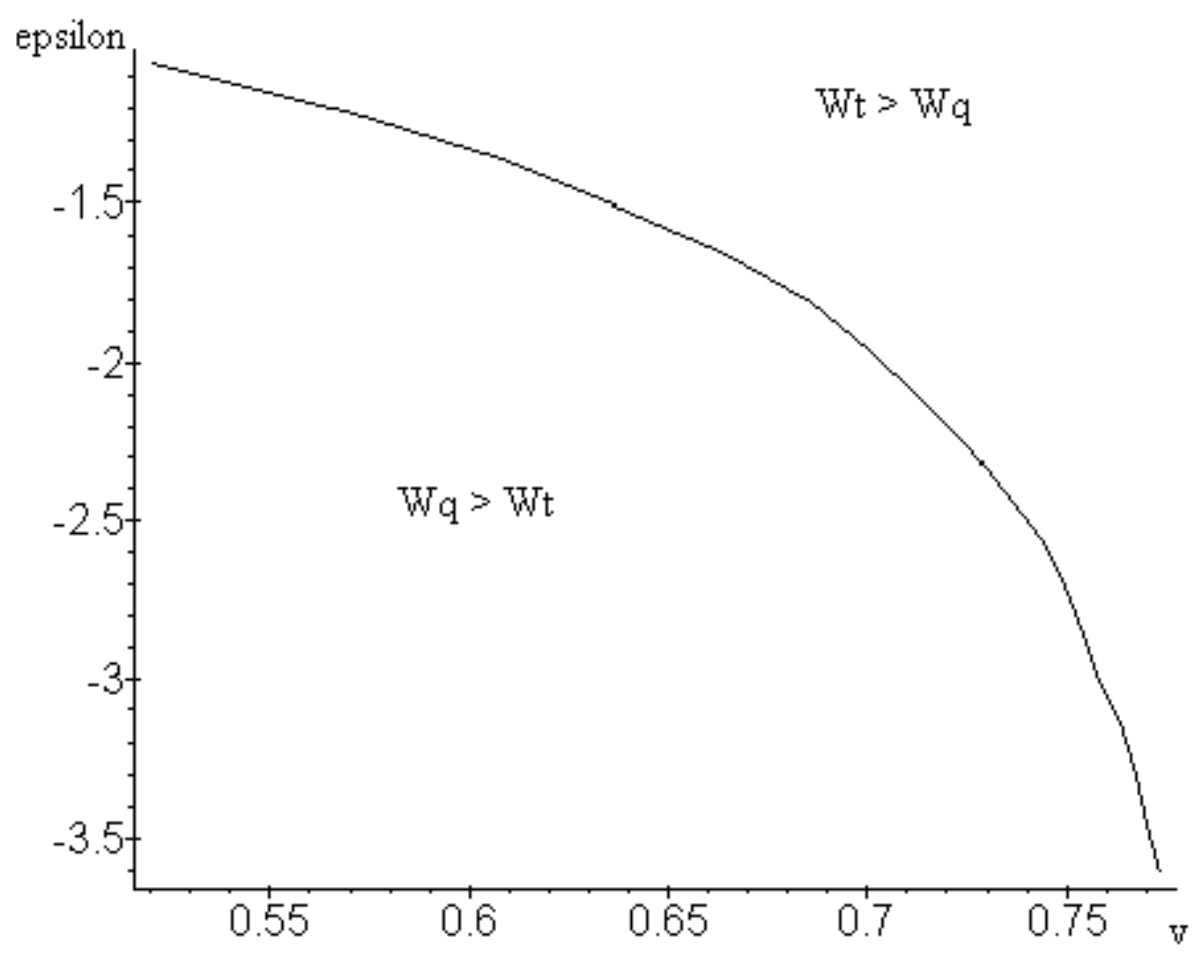


Graph 2b: Combinations of $\mathrm{V}$ and $\mathrm{w}_{\mathrm{r}}$ such that social welfare under queuing (Wq) equals social welfare under targeting (Wt), and the regions where $\mathrm{Wq}>\mathrm{Wt}$ and $\mathrm{Wt}>\mathrm{Wq}$.

$\left(w_{p}=1, \gamma=0.33, \varepsilon=-1\right)$

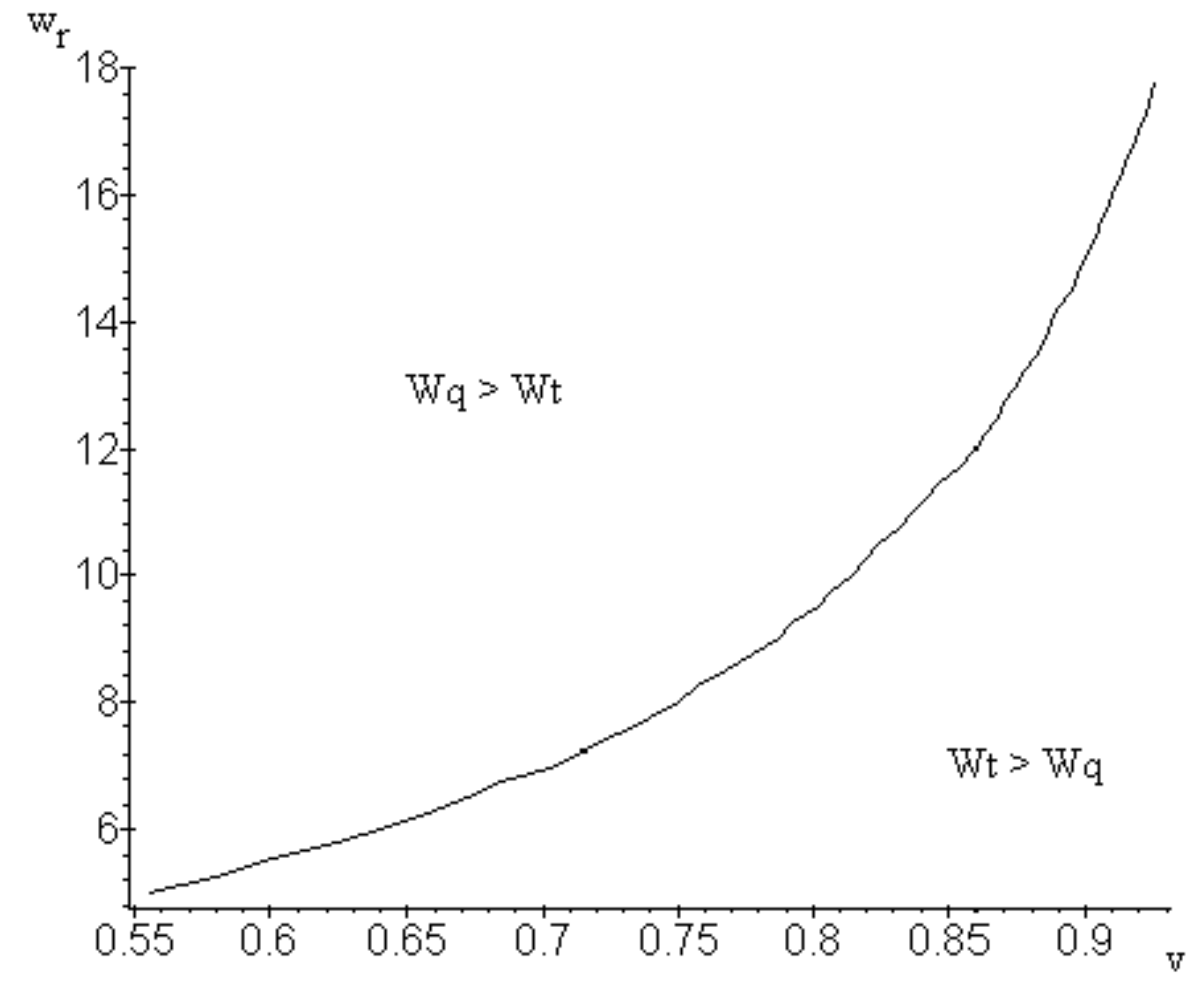


Graph 2c: Combinations of $\varepsilon$ and $\mathrm{w}_{\mathrm{r}}$ such that social welfare under queuing (Wq) equals social welfare under targeting (Wt), and the regions where $\mathrm{Wq}>\mathrm{Wt}$ and $\mathrm{Wt}>\mathrm{Wq}$.

$\left(w_{p}=1, \gamma=0.33, v=0.8\right)$

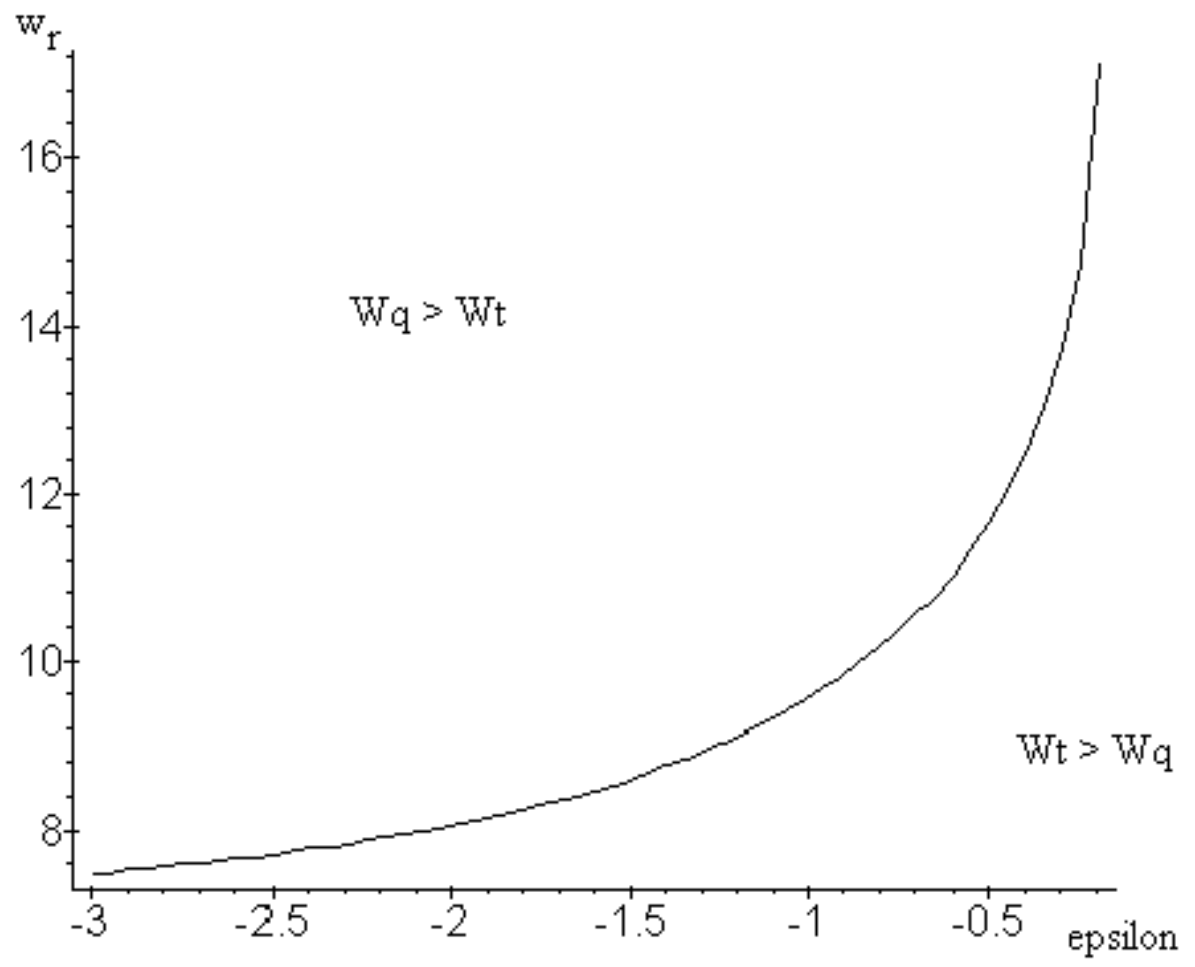




\section{Endnotes}

1. Leitzel (1995, p. 26).

2. It was reported in mid-1995, for example, that the average Russian family received only $\mathbf{4 0} \%$ of its income from wages at officially-reported jobs. OMRI Daily Digest, No. 132, Part I, 10 J uly 1995.

3. Sachs $(1993$, p. 73), notes that the official unemployment rate in Poland was estimated to overstate actual unemployment by approximately one-third. Of course, the holding of informal jobs by those collecting unemployment benefits is not limited to transitional socialist societies.

4. See, e.g., Atkinson and Micklewright (1992, p. 114).

5. EBRD (1995).

6. On local Russian price controls, see, e.g., the discussion in Berkowitz (1996).

7. Weitzman (1977) is an early paper that compares a price system with rationing in meeting a distributional objective, finding that in some circumstances, rationing is preferred. Prell (1996) extends Weitzman's analysis to include the alternative of a price control, though without parallel markets. Other analyses implicitly or explicitly suggest that price controls can differentially favor rich individuals, in part because they create rents which better-off individuals might be in a better position to capture, perhaps corruptly. See, e.g., Bates (1981), Morduch, Brooks, and Urinson (1994), and Shleifer and Vishny $(1992,1993)$.

8. Murrell, Dunn, and Korsun (1996) argue that the culture of policymaking in transitional societies is another factor that tends to favor continued price controls.

9. Besley and Coate (1992). Nichols and Zeckhauser (1982) presented the notion that the imposition of "ordeals," such as queuing, can potentially improve the targeting of a transfer program. In a similar vein, Besley and Coate (1991) showed how a quality differential between private and public provision of a (private) good can support redistributional objectives.

10. See Alexeev and Kaganovich (1995) on distributional constraints on the speed of privatization. Leitzel (1997) contains a fuller discussion of 
substitutes for Western institutions during reform. Berkowitz and DeJ ong (1997) look at continuing price controls and the speed of Russian economic reform.

11. When the social-safety mechanism results in heterogeneity within a group (of rich or poor, as in case 2 below), each subgroup's utility enters the social welfare calculation with the appropriate weight.

12. Barzel (1974) indicates two factors that make it likely that the poor will be those who acquire goods distributed via price controls and queuing: (1) a high price elasticity of demand and (2) a low income elasticity. He goes on to suggest that those conditions are likely to be met in the case of consumer necessities for which close substitutes are available in free-price, parallel markets.

13. Price controls in socialist societies frequently were accompanied by strict limits on the amount of a good that a single individual could purchase once the front of the queue was reached. In the long run, desired purchases could be large relative to the limit allowed, and waiting time would be roughly proportional to the quantity purchased. For a discussion, see Stahl and Alexeev (1986, p. 236). Weitzman (1991) provides an inventory model that makes the alternative assumption that waiting time is independent of the quantity purchased.

14. Numerical simulations with equilibrium queue times above the minimum (but still low enough for a fully separating equilibrium) also were investigated, with qualitatively similar results. The derivation of the expression for $\mathrm{P}^{*}$ and the simulations were carried out using MAPLE $^{\circledR} \mathrm{V}$ software.

15. Alternatively, it could be assumed that the state produces the entire output of the good at the same cost as in the no intervention case, selling some of the output at a low fixed price and the rest at a free market price. A combination of state and private production is another possibility. In the economies in transition, taxing the sales and profits of a relatively few producers may be considerably easier and politically more acceptable than taxing the incomes of a large number of individuals. In Russia, for example, individual income tax collections (2.2\% of GDP in 1995) have been dwarfed by the total amount collected from the enterprise profits tax, VAT, and excise taxes (14.3\% of GDP in 1995). Russian Economic Trends, p. 17.

16. Alternatively, it could be assumed that poor people also will be miscategorized occasionally as being rich. Such an alteration would increase 
the attractiveness of price controls relative to targeting.

17. If instead of a lump-sum tax, workers are taxed a percentage of their earnings, then the taxed individuals no longer increase their labor supply. Simulations conducted using a proportional tax scheme produced results similar in qualitative terms to those reported in section 3 using lump-sum taxes.

18. The qualitative properties displayed in graphs $1 \mathrm{a}$ and $1 \mathrm{~b}$ are reproduced if it is the comparative utility of only the poor people--as opposed to total social welfare--under the two regimes that is examined.

19. Leitzel (1998) examines the distributional impact of price liberalization when price-controlled goods are diverted from the state to the private sector. Shleifer and Vishny $(1992,1993)$ also look at the effects of rent-seeking in the presence of price controls.

20. There is some evidence that such a snowballing of controls led to the Soviet planned economy in the first instance. See the discussion and references in Leitzel (1995, pp. 6-7). 